\title{
Insulin and its analogues- what are they for? (pros and cons)
}

\author{
Zafer Guney* \\ Department of Pharmacology, Gazi University Medical School, Turkey
}

\begin{abstract}
Insulin was discovered by a group of scientists. This hormone has profound effects in carbohydrate and lipid metabolism. Although insulin is a naturally occurring hormone, its analogues have also been synthesized and are in use. In this review, the pharmacokinetic and pharmacodynamic properties of insulin analogues, their adverse effects, clinical effectiveness and economical dimension of their use are discussed.
\end{abstract}

\section{Mechanism of action and its effects}

A group of scientists discovered insulin. Dr. Frederick G. Banting became the first individual to isolate the secretions from the islet cells and not only as a potential treatment for diabetes, but as a hormone which has several metabolic effects, the chemistry skills of his assistant Charles Best, and John MacLeod of the University of Toronto in Canada were the other members of the team [1].

Insulin is a key player in the control of intermediary metabolism, it organizes the use of fuels for either storage or oxidation. Insulin has profound effects on both carbohydrate and lipid metabolism, and significant influences on protein and mineral metabolism. Consequently, derangements in insulin signalling have widespread and devastating effects on many organs and tissues [2].

Insulin signalling begins with binding to its cell surface insulin receptor, and the receptor is a tyrosine kinase. The kinase is subsequently autophosphorylated and activated to tyrosine phosphorylate key cellular substrates that are essential for entraining the insulin response [3].

The insulin receptor is a tyrosine kinase (Figure 1). It functions as an enzyme that transfers phosphate groups from ATP to tyrosine residues on intracellular target proteins. Binding of insulin to the alpha subunits causes the beta subunits to phosphorylate themselves (autophosphorylation), thus activating the catalytic activity of the receptor. The activated receptor then phosphorylates a number of intracellular proteins, which in turn alters their activity, thereby generating a biological response [2].

\section{Insulin and carbohydrate metabolism}

Insulin facilitates entry of glucose into muscle, adipose and several other tissues.

Insulin stimulates the liver to store glucose in the form of glycogen.

A well-known effect of insulin is to decrease the concentration of glucose in blood. One of the major actions of insulin is to reduce blood glucose concentration by affecting both glucose utilisation in peripheral tissues and glucose production by the liver [4-7]. 7, 8].

\section{Insulin and lipid metabolism [2]}

1. Insulin promotes synthesis of fatty acids in the liver.

2. Insulin inhibits breakdown of fat in adipose tissue

Insulin is a naturally occurring hormone, synthesized and secreted by pancreatic $\beta$-cells, and is one of the major regulators of glucose homeostasis regulation system in the body. Impaired glucose metabolism occurs in diabetes mellitus [8]. Approximately $90 \%$ of diabetes cases are of type II (also known as non-insulin-dependent), characterized by insulin resistance and partial insulin deficiency, whereas type I diabetes (also known as insulin-dependent) is characterized by destruction of the insulin producing cells resulting in a complete insulin deficiency(Figure 2).

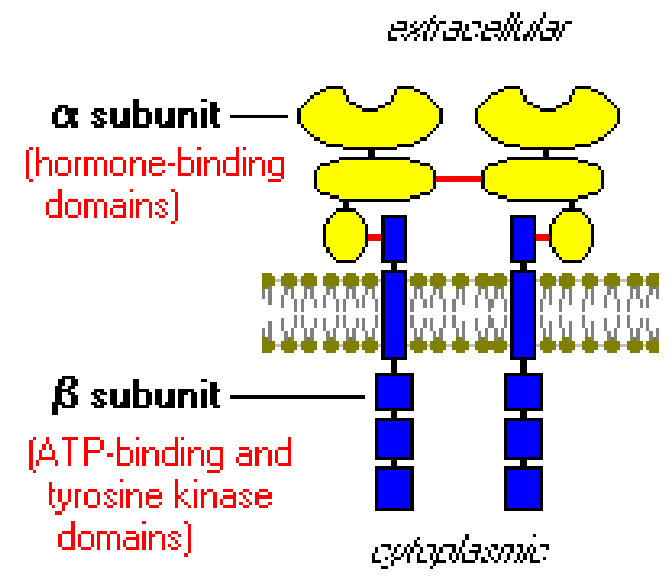

Figure 1. Insulin receptor

*Correspondence to: Zafer Guney, Department of Pharmacology, Gazi University Medical School, Ankara, Turkey, E-mail: zguney@gazi.edu.tr

Key words: insulin, analogues, mechanism of action, adverse effects, effectiveness, pregnancy

Received: August 16, 2019; Accepted: August 26, 2019; Published: August 16, 2019 


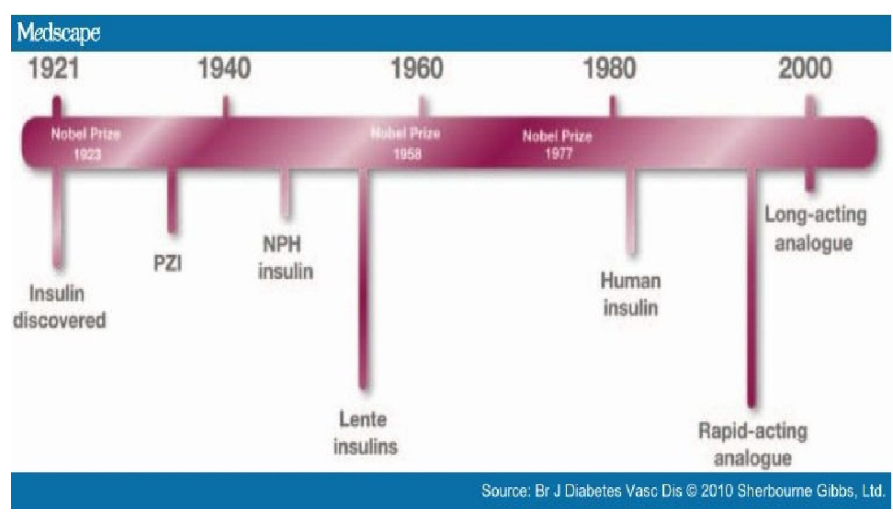

Figure 2. The discovery of insulin and its analogues

Normal fasting concentration levels of insulin in blood range between 50-80 pM [9], therefore requires a highly sensitive and selective detection and quantification. Insulin concentrations in blood samples were first detected by radioimmunoassay [10], which was later replaced by an enzyme-linked immunosorbent assay [11]. Other possible methods are electrochemical impedance spectroscopy [12], surface plasmon resonance [13], carbon nanotube modified electrode [14], and nickel powder modified electrode [15].

\section{Insulin and insulin analogues}

The discovery of insulin by Banting and Best in 1922 represented a milestone in clinical medicine. It has saved the lives of many people who would otherwise have died, but its another and unexpected effect was to transform an acute, rapidly fatal illness into a chronic disease with serious long-term complications [16].

The human insulin molecule is secreted by the pancreas and consists of two polypeptide chains A and B that are linked by two disulphide bridges [17]. In the body, insulin exists as monomers, dimers and as hexamers (consisting of six monomers which self-associate in conjunction with zinc ions).

Insulin complexed to zinc ions dissociates only slowly into insulin monomers. Therefore, these preparations are used to maintain basal insulin levels. During a meal, more rapid-acting monomeric insulin is needed to provide meal-related increased insulin requirements [17]. Two main groups of insulin analogues can be distinguished in 1) shortacting insulin analogues, genetically engineered in such a way that they dissociate more rapidly following injection and in 2) long-acting insulin analogues, which show a delayed absorption or a prolonged duration of action.

The production and use of generic medicines has improved access to medicines in low-income and middle-income countries. For HIV/ AIDS, the production of generic antiretrovirals resulted in prices falling from US\$10 439 per patient per year (produced by the originator) to US\$132 (generic producer) between 2000 and 2006 [17].

\section{Short-acting insulin analogues}

Currently, there are three rapid-acting insulin analogues(insulin lispro, insulin aspart and insülin glulisine) and two long-acting insulin analogues (insulin glargine and insulin detemir) commercially available. Insulin lispro (LysB28, ProB290 human insulin) was the first clinically available insulin analogue . In insulin lispro, the natural amino acid sequence of the B-chain is reversed at positions 28 and 29. As a consequence, there is a proline at position 28 and a lysine at position 29, like in IGF1 [17].
Insulin aspart is obtained by changing proline at position B28 by the negatively charged amino acid aspartic acid. The pharmacokinetic and pharmacodynamic characteristics of insulin aspart are very similar to that of insulin lispro [17].

Insulin glulisine has been developed by substituting aspartic acid at position B3 with lysine and lysine at position B29 with glutamine. These changes also reduce the self-association when injected s.c. and thereby provide a quick biological availability after injection [17].

\section{Long-acting insulin analogues}

This principle has been used for insulin glargine (GlyA21, ArgB31, $\operatorname{ArgB} 32$ human insulin); so it is injected as an acid solution ( $\mathrm{pH} 4.0$ ) and forms a slowly absorbed precipitate in the neutral environment of the subcutis. This property means that it cannot be mixed with neutral formulations of other insulins. Insulin glargine has been produced by substituting asparagine with glycine in the A-chain at position 21 and by adding two arginine residues to the B-chain at position 30 [17].

Another strategy to protract absorption has been to acylate fatty acid species to the insulin molecule to allow reversible albumin-insulin binding in an attempt to protract the time action profile while retaining the practical advantages of a neutral liquid preparation. This strategy has been applied to insulin detemir. In insulin detemir, the 3-amino group on the side-chain of lysine at position B29 is acylated, while threonine at position B30 is removed. After s.c. injection, insulin detemir binds to albumin through this fatty acid chain $[18,19]$. This binding prolonged half-life in pigs to $14.3 \mathrm{~h}$ as compared to $10.5 \mathrm{~h}$ with $\mathrm{NPH}$ insulin and reduces the biological availability of free insulin detemir, making it more predictable in terms of the risk for hypoglycaemic episodes [20-23].

All of the insulin analogues are summarised in table 1.

When regular insulin is injected under the skin, it forms hexamers, which break into dimers, and then monomers. Because insulin is a large protein, only the monomeric insulin molecules are small enough to be absorbed into the systemic circulation [24].

Table 1. Insulin analogues classified by their duration of actions

\begin{tabular}{|c|c|c|}
\hline Type of Insulin & Pharmaceutical and brand name & $\begin{array}{l}\text { Pharmacokinetics } \\
\text { (Duration) }\end{array}$ \\
\hline $\begin{array}{l}\text { Rapid-acting } \\
\text { analogues }\end{array}$ & $\begin{array}{l}\text { Glulisine (Apidra) } \\
\text { Lispro (Humalog) } \\
\text { Aspart (NovoRapid) }\end{array}$ & $\begin{array}{l}2-4 \mathrm{~h} \\
3-5 \mathrm{~h} \\
3-5 \mathrm{~h}\end{array}$ \\
\hline $\begin{array}{l}\text { Short-acting } \\
\text { analogues }\end{array}$ & $\begin{array}{l}\text { Insulin isophane (Humulin R) } \\
\text { Neutral insulin (Actrapid) } \\
\text { Regular Human Insulin \& Isophane Human } \\
\text { Insulin (SciLin N) }\end{array}$ & $\begin{array}{l}5-8 \mathrm{~h} \\
220 \mathrm{minutes} \text { (half-life) } \\
4 \text { minutes (half-life) }\end{array}$ \\
\hline $\begin{array}{l}\text { Intermediate } \\
(\mathrm{NPH}) \text { insulin }\end{array}$ & $\begin{array}{l}\text { Human Insulin Isophane (Humulin N) } \\
\text { INN insulin human (rDNA) (Protaphane) }\end{array}$ & $\begin{array}{l}4-8 \mathrm{~h} \\
5-10 \mathrm{~h}\end{array}$ \\
\hline $\begin{array}{l}\text { Long acting } \\
\text { insulin } \\
\text { analogues }\end{array}$ & $\begin{array}{l}\text { Detemir (Levemir) } \\
\text { Glargine (Lantus) } \\
\text { Insulin degludec (Tresiba) }\end{array}$ & $\begin{array}{l}20-24 \mathrm{~h} \\
24 \mathrm{~h} \\
>25 \mathrm{~h}\end{array}$ \\
\hline $\begin{array}{l}\text { Premixed human } \\
\text { insulins }\end{array}$ & $\begin{array}{l}\text { Insulin isophan and insulin regular (Humulin } \\
\text { 70/30) } \\
\text { Soluble insulin 30\% and isophane insulin 70\% } \\
\text { (Mixtard 30 HM) } \\
\text { Insulin isophan and insulin regular Recombinant } \\
\text { human insulin (SciLin M30-30/70) }\end{array}$ & \\
\hline $\begin{array}{l}\text { Biphasic } \\
\text { Analogue } \\
\text { Insulins }\end{array}$ & $\begin{array}{l}30 \% \text { soluble (rapid-acting) insulin aspart and } \\
70 \% \text { protamine-crystallised (intermediate-acting) } \\
\text { insulin aspart (NovoMix 30) } \\
25 \% \text { insulin lispro solution and } 75 \% \text { insulin } \\
\text { lispro protamine suspension. (Humalog Mix 25) } \\
50 \% \text { insulin lispro solution and } 50 \% \text { insulin } \\
\text { lispro protamine suspension. (Humalog Mix 50) }\end{array}$ & \\
\hline
\end{tabular}


The concentration of traditional insulin products is 100 units $/ \mathrm{mL}$ (U-100). However, the growing number of patients who require very high insulin doses created a market for more concentrated insulin products like U-300 or U-500 [24].

The pharmacokinetics of inhaled and injectable insulins are comparable, apart from an appreciably faster absorption of the former, and both show the same intra-individual variability. The total bioavailability is definitely lower with the inhaled route but is notably increased in smokers. These characteristics can vary according to the inhalation system used. A frequent induced cough, the increase in circulating anti-insulin antibodies, and a potentially higher cost are not really determining obstacles [25].

Expiration of patent protection for recombinant insulins provides the opportunity to introduce biosimilars, onto the market [26]. The main focus is on fast-acting insulin analogues (Humalog; Novolog/ NovoRapid ${ }^{\circ}$ Apidra $)$. Since they differ by few amino acids in chain B, production of one biosimilar for all three drug products is not feasible. However, from clinical data, rapid-acting insulin analogues seem to have similar therapeutic efficacy [26].

Although the majority of patients with diabetes now use biosynthetic human insulin, there are a small number of patients who cannot manage their disease with these biosynthetic human insulins. They need animal sourced insulin to manage their diabetes and they are concerned about the uninterrupted availability of animal-sourced insulin for the future [27].

Unlike antiretroviral drugs or most other medicines, insulin is a biological product and thus creating a biosimilar is more difficult than creating a copy of a chemical entity [28].

Biosimilars face a more stringent regulatory assessment than generics, including the need for clinical trials, which significantly increases costs and timelines to market entry of biosimilars. Although various biosimilar insulins are marketed in countries (such as China, India, and Mexico) with less stringent regulation than, for example, Europe and the USA, it was not until 2015 that a biosimilar insulin received approval from an SRA (Japan's Ministry of Health, Labour and Welfare) to market its biosimilar glargine. This approval provided the first example of a company other than one of the multinational producers that was able to gain approval in a highly regulated market [28].

Assessment of the pharmacokinetic (PK) and pharmacodynamics (PD) properties of a drug formulation is critical to understanding its time-action profile and the drug's benefits [29]. PK parameters determine the concentration of drug and metabolites that are achieved in blood, plasma, or other tissues, whereas PD parameters examine how a drug affects the body. In general, the extent of a drug's PD interactions within an individual is affected by drug PK parameters, such as absorption, distribution, metabolism, excretion and, frequently, drug concentration. However, the relationship between PK and PD is less direct with insulins that exert pharmacologic effects through binding to cell surface receptors [30]. In patients with diabetes, altered insulin sensitivity can result in altered PD activity for the same PK concentration in different individuals.

\section{Adverse effects}

The most common adverse drug reactions for both groups were similar and included infection, central nervous system disorders, gastrointestinal events, hypoglycemia, injection site reactions and musculoskeletal complaints [24].
The major clinical studies on insulin showed that the safety and effectiveness of human biosynthetic insulin and animal-sourced insulin are comparable. In addition, the number and types of adverse reactions reported with both types of insulins were similar. In fact, adverse reactions such as hypoglycemia (low blood glucose), may occur while taking either type of insulin without any major difference [27].

Hypoglycemia can occur regardless of what type of insulin you take and can cause fatigue, sweating, heart palpitations, disturbed behaviour, hunger, loss of consciousness, or in extreme circumstances even death and can occur without recognizable symptoms.

Several types of hypersensitivity reactions to insulin preparations have been described. These reactions may be caused by the insulin itself or by additives within the preparation. Hypersensitivity reactions to insulin are rare with human insulins and insulin analogues. However, some types of reactions are serious and even life-threatening and may have a significant detrimental impact on the patient's diabetic management [31]. Local reactions may present as erythema, swelling, heat, or subcutaneous nodules [32]. They usually occur within the first two weeks of therapy, then disappear [32]. Immunologic responses to insulin, particularly animal insulin formulations, include the formation of anti-insulin antibodies.

An unusual ocular disturbance during the beginning of therapy is bilateral presyopia (blurry vision). Dermatologic reactions to insulin can result in lipohypertrophy or lipoatrophy [32].

Adverse effect reports of malignancies have caused concern regarding the long-term use of these therapies. Recently published studies investigating a possible relationship between insulin analogues, in particular insulin glargine, and the risk of cancer are currently under review of the European Medicines Association (EMA) [33].

There are no conclusions that can be drawn from the studies about the long-term effects of the interventions on the risk of diabetes-related complications and overall mortality [34].

\section{Clinical effectiveness}

Diabetes and cardiovascular outcomes are closely linked. Many studies have implicated insulin resistance and hyperinsulinemia as a major factor for poor cardiovascular outcomes. Additional studies link the anabolic effects of therapeutic insulin to weight gain, along with hypoglycemia, which may further aggravate cardiovascular risk in this population. Though good glycemic control has been shown to improve microvascular risks in type 1 and type 2 diabetes, what are the known cardiovascular effects of insulin therapy? The ORIGIN trial suggests at least a neutral effect of the basal insulin glargine on cardiovascular outcomes. Recent studies have demonstrated that ultra-long-acting insulin analogs like insulin degludec are non-inferior to insulin glargine with regard to cardiovascular outcomes [34].

A randomized crossover study in healthy male subjects revealed a hepato-preferential effect and relatively decreased peripheral action of polyethyleneglicol (PEG)lispro on glucose homeostasis that might better recreate the physiological actions of endogenous insulin, which is secreted into the portal vein [35]. In the open-label IMAGINE 1 trial, patients receiving PEGlispro reported a statistically significant higher rate of severe hypoglycaemic events; however, in the larger, blinded IMAGINE 3 trial the rate of severe hypoglycaemic events for PEGlispro treatment was numerically lower than for IGlar U100, but not statistically significant $[36,37]$. In a 52-week trial comparing safety and efficacy of PEGlispro versus IGlar U100 in patients with type 2 diabetes 
uncontrolled on basal insulin or $\geq 3$ oral antidiabetic drugs, PEGlispro provided superior $\mathrm{HbAlc}$ reductions at a $60 \%$ lower rate of nocturnal hypoglycaemia, but with higher mean (standard deviation) levels of triglycerides, alanine aminotransferase, aspartate aminotransferase and liver fat content versus U100 after 52 weeks of treatment [38]. PEGlispro was associated with less weight gain versus U100 in patients with type 2 diabetes not previously using insulin (IMAGINE-2), [39] those using basal insulin with mealtime insulin (IMAGINE-4) [40] and similar weight gain versus U100 in patients currently using a basal insulin (IMAGINE-5) [38].

Collectively, the trials demonstrated an improved balance between glycaemic control and tolerability for both analogues compared to $\mathrm{NPH}$, regardless of regimen and diabetes type. Neither once-daily glargine nor detemir reliably provides 24 -h basal insulin replacement in all patients with type 1 diabetes; a waning of effect frequently obliges twice-daily administration [39].

Established rapid-acting and long-acting insulin analogues have enabled more patients with type 1 diabetes mellitus to reach better glucose targets, with lower hypoglycaemia rates and a better quality of life than was possible with short-acting and long-acting human insulin [41]. Compliance with the insulin therapy is important in preventing the adverse clinical effects of the disease [42]. In human beings the $\beta$-cells of pancreatic islets of Lang rhans synthesize insulin from a single-chain precursor of 110 amino acids termed preproinsulin. Insulin was purifi ed and crystallized by Abel within a few years of its discovery. Sanger established the amino acid sequence of insulin in 1960 and it was synthesized in 1963 . However Hodgkin and co-workers have elucidated insulin's three-dimensional structure in $1972[43,44]$.

In 1980s with the help of recombinant DNA technology, human insulin were discovered which replaced animal insulin's. With the advent of high-pressure liquid chromatographic technique, the level of purifi cation of animal-sourced insulin's has reached as high as $99 \%$, whereas the purity level of synthetic human insulin's made via recombinant DNA has only attained a maximum purity level of $97 \%$, which raises questions about the claim of synthetic insulin's purity related to animalsourced insulin varieties Human insulin's have reduced the adverse eff ects of animal insulin's such as insulin allergy, insulin resistance and insulin lipodisatrophy $[43,44]$.

The second-generation basal insulin analogues provide physicians with new treatment options for achieving targeted glycaemic control. While providing similar efficacy in lowering $\mathrm{HbAlc}$ to first-generation insulin analogues, the newer insulin treatment options provide additional clinical benefits, including a more stable, ultra-long duration of action that enables once-daily administration with flexibility in daily injection time, together with a lower risk of hypoglycaemia [45].

The results of another study found no clear benefits of shortacting insulin analogues over regular human insulin in people with type 2 diabetes. The certainty of the evidence was poor and results on patient-relevant outcomes, like all-cause mortality, microvascular or macrovascular complications and severe hypoglycaemic episodes were sparse [46].

The need of insulin analogues arises from the fact that the human insulin injections have a lag period of around 30 minutes between administration and onset of action. As a result, regular human insulin is not able to mimic the human physiology. Endogenous insulin, after secretion from the pancreas, enters the portal circulation, after which it reaches the systemic circulation. On the other hand, exogenous human insulin, after injection into sub-cutaneous tissue, enters the systemic circulation, and then about $10 \%$ of the originally administered insulin reaches the portal circulation. Thus, the portal and systemic gradient of insulin is inverted in the case of exogenous insulin. Rapid-acting insulin analogs overcome this by being more in tune with the physiological rise and fall of glucose values after each meal [47].

Areas of particular interest for insulin research include [48]:

The effect of time and/or intensity of insulin treatment on the likelihood of developing malignancy.

Elucidation of potential mechanisms e.g. cancer initiation/ promotion.

\section{Dose-response effects.}

The limitations of the relatively short duration of the clinical development programs to study long-term safety e.g. the potential effects of long-term treatment on the initiation or promotion of malignancy.

Identification of risk factors for developing malignancy in patients treated with insulin of insulin analogues e.g. indication for treatment, age, sex, disease (including severity), body mass index (BMI), menopausal status, parity, socioeconomic status, prior and during treatment.

Methodologies for early clinical detection of malignancy.

Methodologies for screening/predicting patients at high risk of developing malignancy.

Detection of differences between different insulins and insulin analogues.

Biphasic insulin analogues can target both fasting and postprandial hyperglycaemia. A practical and feasible option is to initiate insulin with one or more biphasic preparations at mealtimes. Individual titration of dose and frequency of daily injections with biphasic insulin preparations has the potential for improving glycaemic control with a high degree of patient acceptance. Drawbacks include a more rigid regimen, a relative lack of flexibility, and a somewhat higher degree of glycaemic variability and hypoglycaemia when compared to multiple daily basal-bolus injections [48].

Human regular (U-500) insulin is efficacious and safe for patients with type 2 diabetes who require a high dosage of insulin to control hyperglycemia. However, health care professionals should be well educated and vigilant about patient safety issues regarding the drug's prescription, dosing, and administration [49].

Evidence concerning the efficacy and safety of glucose-lowering agents for treating pre-existing and new-onset diabetes in kidney transplant recipients is limited [50].

Basal insulin therapy can provide satisfactory glucose control in more than $70 \%$ of patients with type 2 diabetes. Long diabetes duration, obesity, insulin resistance and female sex indicate a need for further treatment intensification [51].

Older adults are at an increased risk of developing type 2 diabetes mellitus (T2DM). Although oral agents (i.e., metformin) are the preferred first-line therapy, older adults often eventually require the addition of insulin to control their blood glucose. Long-acting insulin analogues are the preferred insulin products for older adults with T2DM. Insulin degludec and insulin glargine U-300 are both new generations long-acting insulins [52]. 


\section{Pharmacoeconomics}

There is a pharmacoeconomic advantage of insulin analogs due to improved glycemic control, improved adherence to therapy (less fear of hypoglycemia and weight gain), and lower rates of hypoglycemia [53].

In patients who are prone to severe hypoglycaemia, using a full analogue regimen is rapidly cost saving and should therefore be the standard of care in all patients with type 1 diabetes mellitus [54].

The cost-effectiveness of insulin analogues depends on the type of insulin analogue and whether the patient receiving the treatment has type 1 or type 2 diabetes. With the exception of rapid-acting insulin analogues in type 1 diabetes, routine use of insulin analogues, especially long-acting analogues in type 2 diabetes, is unlikely to represent an efficient use of finite health care resources [55].

Studies of incremental cost-effectiveness ratio per quality adjusted life year gained generally demonstrated that insulin analogues could be cost-effective compared with conventional human insulin. The drug costs were higher in the insulin analogues group than the conventional human insulin, but this was partly offset by reduced complication costs [56].

Compared with human insulin, insulin detemir was likely to be cost-effective for type 1 diabetes mellitus based on the willingness to pay threshold in Sweden (SEK 100,000 per QALY gained), U.K. ( 30,000 per QALY gained) and the U.S.A. (USD \$ 50,000 per QALY gained) [57-60].

The benefit of insulin aspart compared with human insulin in adult patients is unclear due to a lack of data or poor-quality data; an additional benefit is therefore not proven. In patients without a higher than usual risk of hypoglycaemia, overall, the studies show similar results between insulin lispro and human insulin. On the basis of the data available, it is unclear whether insulin lispro has an additional benefit in patients with an increased risk of serious hypoglycaemic events.

Due to a lack of data, there is no evidence of an additional benefit of insulin glulisine versus human insulin. There is an indication of an additional benefit of insulin lispro versus insulin glulisine. This indication is solely based on a lower rate of serious nocturnal hypoglycaemic events under insulin lispro observed in one study.

Exenatide, the gliptins and detemir were all clinically effective. The long-acting insulin analogues glargine and detemir appeared to have only slight clinical advantages over NPH but had much higher costs and did not appear to be cost-effective as first-line insulins for type 2 diabetes. Neither did exenatide appear to be cost-effective compared with NPH but, when used as third drug after failure of dual oral combination therapy, exenatide appeared cost-effective relative to glargine in this analysis [61].

Current evidence indicates that insulin analogues are cost effective for T1DM; however, evidence for their use in T2DM is not convincing. Additional evidence regarding compliance and efficacy is required to support the broader use of long-acting and biphasic insulin analogues in T2DM. The value of insulin analogues depends strongly on reductions in hypoglycaemia event rates and its efficacy in lowering glycated haemoglobin $\left(\mathrm{HbA}_{1 \mathrm{c}}\right)$ [62].

\section{Insulin in pregnancy}

One trial compared Lispro insulin with regular insulin and provided very low-quality evidence for the outcomes. There were seven episodes of pre-eclampsia in the Lispro group and nine in the regular insulin group, with no clear difference between the two groups. There were five caesarean sections in the Lispro group and nine in the regular insulin group, with no clear difference between the two groups. There were no cases of fetal anomaly in the Lispro group and one in the regular insulin group, with no clear difference between the groups. Macrosomia, perinatal deaths, episodes of birth trauma including shoulder dystocia, nerve palsy, and fracture, and thecomposite outcome measure of neonatal morbidity were not reported [63].

The use of lispro was associated with lower rates of neonatal jaundice and severe maternal hypoglycemia than regular insulin. Lispro use was also associated with higher birth weight and an increased incidence of large for gestational age births compared with regular insulin. Rates of cesarean section and macrosomia were similar in pregnant women treated with aspart and regular insulin. Birth weights and rates of severe maternal hypoglycemia, respiratory dysfunction syndrome, and neonatal intensive care unit admission were similar after pregnant women were treated with glargine and NPH insulin [64].

In a retrospective population-based cohort study, the authors found no increase in the risk of congenital anomalies in fetuses exposed to insulin analogues in the first trimester compared with those exposed to human insulin. Furthermore, a significantly lower risk of congenital heart defects was observed with exposure to insulin analogues [65].

With the availability of first published data on the properties of a biosimilar long-acting insulin, and with some data on copies of insulin in other countries, it is now possible to assess what will be meant by 'similarity', and what the issues surrounding such an assessment are. Furthermore, the issues around immunogenicity for biosimilar insulins are becoming clearer. The release of data on the Lilly insulin glargine approval in the EU shows the complexity of biosimilar approval and is for the more general understanding of such assessments for the future [66].

Increasing competition in insulin manufacture could lead to large price reductions, potentially enabling the scale-up of access to treatment [67].

It is important to note that FDA pregnancy categories are not used after 2015 [68]. Insulin therapy remains the standard of care for type 1 diabetes, type 2 diabetes, and uncontrolled gestational diabetes mellitus (GDM) during pregnancy. Regular insulin, insulin aspart, insulin lispro, and NPH have the most human pregnancy data [68].

Screening for insulin resistance can be advised to all pregnant women. Insulin sensitivity can be improved in these women by modifying lifestyle, diet, and physical activity. Balanced diet providing required quantity of macro and micro nutrients with good amount of dietary fibers can be prescribed [69]. Avoidance of sedentary lifestyle and increasing amount of activity should be advised before, during and after pregnancy. Mild exercises such as walking and climbing stairs can be advised for women with increased insulin resistance during pregnancy [70]. Such intervention should be done at an early stage well before the insulin resistance related complication develops [71]. As pregnancy advances, IR increases. Increased IR is associated with poor maternal and fetal outcome. Screening of all pregnancy for IR and early intervention may help to reduce the associated complications [71].

Aspart, glargine, and detemir are safe treatment options for diabetes during pregnancy; these insulin analogs did not increase complications for the mothers or fetuses in our study. However, lispro was related to higher birth weight in neonates. More high-quality randomized controlled trials are needed to clarify the best treatment options for diabetes during pregnancy [64]. 


\section{Conclusions}

Healthcare professionals are encouraged to risk assess electronic and paper systems used to prescribe, dispense and administer high strength/fixed-combination insulin products, carefully check the product strength selected in electronic systems and risk assess storage arrangements for high-strength/fixed-combination insulin products to help ensure selection of the correct strength and to avoid confusion with other products [72].

Treatment with insulin analogues compared with conventional human insulin appeared to offer minor benefit in terms of glycaemic control as reflected in $\mathrm{HbAlc}$ level, postprandial blood glucose and fasting blood glucose but have advantages in terms of reduced occurrence of hypoglycaemia, particularly nocturnal hypoglycaemia and severe hypoglycaemia as reported in some studies. While the adverse events (excluding hypoglycaemia episodes) were found to be similar in both treatment groups, patients treated with insulin analogues showed greater treatment satisfaction and less weight gain. Hence, it is recommended that insulin analogues should be made available for treatment of all type 1 diabetes mellitus and for type 2 diabetes mellitus who have recurrent hypoglycaemia. More high quality clinical trials are warranted to provide evidence on long term safety and effectiveness of insulin analogues. Although insulin analogues could be considered cost-effective in some countries, international comparisons of economic evaluations are limited [71].

Increasing competition in insulin manufacture could lead to large price reductions, potentially enabling the scale-up of access to treatment [67].

The efficacy of insulin treatment seems to vary little between the available products, however doses needed to achieve similar effects vary; units used per $\mathrm{HbAl} \mathrm{c}$ reduction could be a relevant parameter for the choice of insulin.

\section{References}

1. Falck S (2018) Who discovered insulin? FACP. Medical News Today.

2. Physiologic Effects of Insulin (2019) Available at: www.vivo.colostate.edu/hbooks/ pathphys/endocrine/pancreas/insulin_phys.html

3. Posner BI (2017) Insulin Signalling: The Inside Story. Can J Diabetes 41: 108-113. [Crossref]

4. Bodo RC, Steele R, Altszuler N, Dunn A, Bishop JS (1963) On the hormonal regulation of carbohydrate metabolism; studies with 4C glucose. Recent Prog Horm Res 19: 445488. [Crossref]

5. HETENYI G, WRENSHALL GA, BEST CH (1961) Rates of production, utilisation, accumulation and apparent distribution space of glucose. Effects of insulin in dogs using a validated tracer method. Diabetes 10: 304-311. [Crossref]

6. Hetenyi G (1971) The regulation of glucose production and utilisation in the intact animal. Acta Diabetol Lat 8: 213-227. [Crossref]

7. Vranic M, Wrenshall GA (1968) Matched rates of insulin infusion and secretion and concurrent tracer - determined rates of glucose appearance and disappearance in fasting dogs. Can J Physiol Pharmacol 46: 383-390. [Crossref]

8. Bisker G, Iverson M, Ahn J, Strano MS (2015) A Pharmacokinetic Model of a Tissue Implantable Insulin Sensor. Adv Healthc Mater 4: 87-97. [Crossref]

9. Yalow RS, Berson SA (1960) Immunoassay of endogenous plasma insulin in man. $J$ Clin Invest 39: 1157-1175. [Crossref]

10. Albano JDM, Ekins RP, Maritz G, Turner RC (1972) A sensitive, precise, radioimmunoassay of serum insulin relying on charcoal separation of bound and free hormone moieties. Acta Endocrinologica 70: 487-509. [Crossref]

11. Pekar AH, Frank BH (1972) Conformation of Proinsulin. A comparison of insulin and pro-insulin Self-Association at neutral pH. Biochemistry 11: 4013-4016. [Crossref]
12. MacDonald MJ, Gapinski JP (1989) A rapid ELISA for measuring insulin in a large number of research samples. Metabolism Clinical and Experimental 38: 450-452. [Crossref]

13. Xu M, Luo X, Davis JJ (2013) The label free picomolar detection of insulin in blood serum. Biosensors and Bioelectronics 39: 21-25. [Crossref]

14. Frasconi M, Tortolini C, F. Botrè, F. Mazzei (2010) Multifunctional Au nanoparticle dendrimer-based surface plasmon resonance biosensor and its application for improved insulin detection. Analytical Chemistry 82: 7335-7342. [Crossref]

15. Wang J, Musameh M (2004) Electrochemical detection of trace insulin at carbonnanotube-modified electrodes. Analytica Chimica Acta 511:33-36.

16. Salimi A, Roushani M, Soltanian S, Hallaj R (2007) Picomolar Detection of Insulin at Renewable Nickel Powder-Doped Carbon Composite Electrode. Analytical Chemistry 79: 7431-7438.

17. Varewijck AJ, Janssen JA (2012) Insulin and its analogues and their affinities for the IGF1 receptor. Endocrine-Related Cancer 19: F63-F75. [Crossref]

18. Owens DBA (2000) Diabetes, current perspectives. In Designer Insulins: Have They Revolutionized Insulin Therapy?. DJ Betteridge. Martin Dunitz Ltd: London, UK

19. Vigneri R, Squatrito S, Sciacca L (2010) Insulin and its analogs: actions via insulin and IGF receptors. Acta Diabetologica 47: 271-278. [Crossref]

20. Markussen J, Havelund S, Kurtzhals P, Andersen AS, Halstrom J, et al. (1996) Soluble, fatty acid acylated insulins bind to albumin and show protracted action in pigs. Diabetologia 39: 281-288. [Crossref]

21. Vague P, Selam JL, Skeie S, De Leeuw I, Elte JW, et al. (2003) Insulin detemir is associated with more predictable glycemic control and reduced risk of hypoglycemia than NPH insulin in patients with type 1 diabetes on a basal-bolus regimen with premeal insulin aspart. Diabetes Care 26: 590-596. [Crossref]

22. Havelund S, Plum A, Ribel U, Jonassen I, Volund A, et al. (2004) The mechanism of protraction of insulin detemir, a long-acting, acylated analog of human insulin Pharmacological Research 21: 1498-1504. [Crossref]

23. Heise T, Nosek L, Ronn BB, Endahl L, Heinemann L, et al. (2004) Lower withinsubject variability of insulin detemir in comparison to NPH insulin and insulin glargine in people with type 1 diabetes. Diabetes 53: 1614-1620. [Crossref]

24. Painter NA, Sisso E (2016) An Overview of Concentrated Insulin Products. Diabetes Spectr 29: 136-140. [Crossref]

25. Becquemin MH, Chaumuzeau JP (2010) Inhaled insulin: a model for pulmonary systemic absorption? Rev Mal Respir 27: e54-65. [Crossref]

26. Franzè S, Cilurzo F, Minghetti P (2015) Insulin biosimilars: the impact on rapid-acting analogue-based therapy. BioDrugs 29: 113-121. [Crossref]

27. Food and Drugs Act. Available at: www.healthcanada.gc.ca/iyh

28. Perrin C, Ewen M, Beran D (2017) The role of biosimilar manufacturers in improving access to insulin globally. Lancet Diabetes Endocrinol 5: 578.

29. Tozer TN, Rowland M(2006) Introduction to pharmacokinetics and pharmacodynamics The quantitative basis of drug therapy. Chapter 1: Opening comments. In: Klingler A, (Edtr). Baltimore: Lippincott Williams \& Wilkins: 2-3.

30. Arnolds S, Kuglin B, Kapitza C, Heise T (2010) How pharmacokinetic and pharmacodynamic principles pave the way for optimal basal insulin therapy in type 2 diabetes. Int J Clin Pract 64: 1415-1424. [Crossref]

31. Celik E, Celik M (2019) Hypersensitivity Reactions to Insulins and its Management Endocrinology and Metabolic Research 4: 4.

32. Insulin Side Effects. Available at : https://www.drugs.com/sfx/insulin-side-effects.html

33. European Medicines Agency 2011 Priorities for Drug Safety Research Insulin/insulin analogues and cancer. Patient Health Protection.

34. Dongerkery SP, Schroeder PR, Shomali ME (2017) Insulin and Its Cardiovascular Effects: What Is the Current Evidence? Current Diabetes Reports 17: 120. [Crossref]

35. Henry RR, Mudaliar S, Ciaraldi TP, Armstrong DA2, Burke P, et al. (2014) Basal insulin peglispro demonstrates preferential hepatic versus peripheral action relative to insülin glargine in healthy subjects. Diabetes Care 37: 2609-2615. [Crossref]

36. Garg S, Dreyer M, Jinnouchi H, Mou J, Qu Y, et al. (2016) A randomized clinical trial comparing basal insulin peglispro and insulin glargine, in combination with prandial insulin lispro, in patients with type 1 diabetes: IMAGINE 1. Diabetes Obes Metab 2: 25-33. [Crossref] 
37. Bergenstal RM, Lunt H, Franek E, Travert F, Mou J, et al. (2016) Randomized, double-blind clinical trial comparing basal insulin peglispro and insulin glargine, in combination with prandial insulin lispro, in patients with type 1 diabetes: IMAGINE 3. Diabetes Obes Metab 64: A250. [Crossref]

38. Davies MJ, Russell-Jones D, Selam JL, Bailey TS, Kerényi Z, et al. (2015) Basal insulin peglispro versus insulin glargine in insulin-naïve type 2 diabetes: IMAGINE 2 randomized trial. Diabetes Obes Metab 64: A24. [Crossref]

39. Devries JH, Nattrass M, Pieber TR (2007) Refining basal insulin therapy: what have we learned in the age of analogues? Diabetes Metab Res Rev 23: 441-454. [Crossref]

40. Heise T, Mathieu C (2017) Impact of the mode of protraction of basal insulin therapies on their pharmacokinetic and pharmacodynamic properties and resulting clinical outcomes. Diabetes Obes Metab 19: 3-12. [Crossref]

41. Mathieu C, Gillard P, Benhalima K (2017) Insulin analogues in type 1 diabetes mellitus: getting better all the time. Nat Rev Endocrinol 13: 385-399. [Crossref]

42. Heinemann L, Starke AAR, Hohmann A, Berger M (1992) Timing between the subcutaneous administration of insulin and consumption of a carbohydrate rich meal. Horm Metab Res Suppl 26: 137-39. [Crossref]

43. Goodman and Gilman's the Pharmacological Basis of Therapeutics, 11th Edition.

44. Wilson, Griswold (2004) Textbook of Organic Medicinal and Pharmaceutical Chemistry (11th Edn). New York, Lippincott Williamsons and Wilkins: Philadelphia.

45. Mauricio D, Hramiak I (2018) Second-generation Insulin Analogues - a Review of Recent Real-world Data and Forthcoming Head-to-head Comparisons. Eur Endocrinol 14: 2-9. [Crossref]

46. Fullerton B, Siebenhofer A, Jeitler K, Horvath K, Semlitsch T, et al. (2018) Short-acting insulin analogues versus regular human insulin for adult, non-pregnant persons with type 2 diabetes mellitus. Cochrane Database of Systematic Reviews 12: CD013228. [Crossref]

47. Kalra S (2015) Basal insulin analogues in the treatment of diabetes mellitus: What progress have we made? Indian J Endocrinol Metab 19: S71-S73. [Crossref]

48. Rizvi AA (2016) Treatment of type 2 diabetes with biphasic insulin analogues. Eur Med J Diabetes 4: 74-83. [Crossref]

49. Segal AR, Brunner JE, Burch FT, Jackson JA (2010) Use of concentrated insulin human regular (U-500) for patients with diabetes. Am J Health-Syst Pharm 67: 15261535. [Crossref]

50. Lo C, Jun M, Badve SV, Pilmore H, White SL, et al. (2017) Glucose-lowering agents for treating pre-existing and new-onset diabetes in kidney transplant recipients. Cochrane Database Syst Rev 2: CD009966. [Crossref]

51. Buchholz C, Kahle-Stephan M, Meier JJ, Nauck MA (2019) Clinical Predictors of the Need for Further Treatment Escalation in Patients with Type 2 Diabetes on Basal Insulin Therapy - A Retrospective Observational Study. Exp Clin Endocrinol Diabetes.

52. Stailey M, Conway SE (2017) Review of the Next Generation of Long-Acting Basal Insulins: Insulin Degludec and Insulin Glargine. Consult Pharm 32: 42-46. [Crossref]

53. Grunberger G (2014) Insulin Analogs Are They Worth It? Yes!. Diabetes Care 37: 1767-1770. [Crossref]

54. Heise T, Mathieu C (2017) Impact of the mode of protraction of basal insulin therapies on their pharmacokinetic and pharmacodynamic properties and resulting clinical outcomes. Diabetes Obes Metab 19: 3-12. [Crossref]

55. Cameron CG, Bennett HA (2009) Cost-effectiveness of insulin analogues for diabetes mellitus. CMAJ 180: 400-407. [Crossref]
56. Shafie AA, Ng CH, Tan YP, Chaiyakunapruk N (2017) Systematic Review of the Cost Effectiveness of Insulin Analogues in Type 1 and Type 2 Diabetes Mellitus. Pharmacoeconomics 35: 141-162. [Crossref]

57. Valentine WJ, Aagren M, Haglund M, Ericsson A, Gschwend MH (2011) Evaluation of the long-term cost-effectiveness of insulin detemir compared with neutral protamine hagedorn insulin in patients with type 1 diabetes using a basal-bolus regimen in Sweden. Scand J Public Health 39: 79-87. [Crossref]

58. Palmer AJ, Valentine WJ, Ray JA, Foos V, Lurati F, et al. (2007) An economic assessment of analogue basal-bolus insulin versus human basal-bolus insulin in subjects with type 1diabetes in the UK. Current Medical Research and Opinion 23: 895-901. [Crossref]

59. Valentine WJ, Palmer AJ, Erny-Albrecht KM, Ray JA, Cobden D, et al. (2004) Costeffectiveness of basal insulin from a US Health System Perspective: Comparative Analyses of Detemir, Glargine, and NPH . 2006;23 (2) :191-207Palmer AJ, Roze S, Valentine WJ et al. Cost-effectiveness of detemir-based basal/bolus therapy for type 1 diabetes in a UK setting: an economic analysis based on meta-analysis results of four clinical trials. Current Medical Research and Opinion 20: 1729-17466. [Crossref]

60. Waugh N, Cummins E, Royle P, Clar C, Marien M, et al. (2010) Newer agents for blood glucose control in type 2 diabetes: systematic review and economic evaluation. Health Technol Assess 14: 1-248. [Crossref]

61. Shafie AA, Ng CH, Tan YP, Chaiyakunapruk N (2017) Systematic Review of the Cost Effectiveness of Insulin Analogues in Type 1 and Type 2 Diabetes Mellitus. Pharmacoeconomics 35: 141-162. [Crossref]

62. O’Neill SM, Kenny LC, Khashan AS, West HM, Smyth RMD, et al. (2017) Different insulin types and regimens for pregnant women withpre-existing diabetes. Cochrane Database of Systematic Reviews 2: CD011880. [Crossref]

63. Lv S, Wang J, Xu Y (2015) Safety of insulin analogs during pregnancy: a metaanalysis. Arch Gynecol Obstet 292: 749-756. [Crossref]

64. Wang H, Wender-Ozegowska E, Garne E, Morgan M, Loane M, et al. (2018) Insulin analogues use in pregnancy among women with pregestational diabetes mellitus and risk of congenital anomaly: a retrospective population-based cohort study. BMJ Open 8: e014972. [Crossref]

65. Heinemann L, Home PD, Hompesch M (2015) Biosimilar insulins: guidance for data interpretation by clinicians and users. Diabetes Obes and Metab 17: 911-918. [Crossref]

66. Gotham D, Barber MJ, Hill A (2018) Production costs and potential prices for biosimilars of human insulin and insulin analogues. Dzintars Gotham, Melissa J Barber, Andrew Hill. BMJ Glob Health 3: e000850. [Crossref]

67. Blum AK (2016) Insulin Use in Pregnancy: An Update Blum AK. Diabetes Spectr 29: 92-97. [Crossref]

68. McAuley KA, Williams SM, Mann JI, Goulding A, Chisholm A, et al. (2002) Intensive lifestyle changes are necessary to improve insulin sensitivity: a randomized controlled trial. Diabetes Care 25: 445-452. [Crossref]

69. Tobias DK, Zhang C, Van Dam RM, Bowers K, Hu FB (2011) Physical activity before and during pregnancy and risk of gestational diabetes mellitus: a meta-analysis Diabetes Care 34: 223-229. [Crossref]

70. Sonagra AD, Biradar SM, Dattatreya K, Murthy DSJ (2014) Normal Pregnancy- A State of Insulin Resistance. J Clin Diagn Res 8: CC01-CC03. [Crossref]

71. MaHTAS (2012) Insulin Analogues. Health Technology Assessment Report, Medical Development Divison, Ministry of Health Malaysia.

Copyright: (C2019 Guney Z. This is an open-access article distributed under the terms of the Creative Commons Attribution License, which permits unrestricted use, distribution, and reproduction in any medium, provided the original author and source are credited. 